\title{
Extracorporeal shock wave therapy in the management of insertional plantar fasciitis: the ASSERT database
}

\author{
Gayle Maffulli ${ }^{1}$ \\ Johnny Padulo 2,3 \\ Enzo Iuliano 4 \\ John Furia ${ }^{5}$ \\ Jan Rompe 6 \\ Nicola Maffulli ${ }^{7,8}$
}

1 Wholelife Clinics, London, UK

2 University eCampus, Via Isimbardi, Novedrate, Italy

3 Faculty of Kinesiology, University of Split, Split, Croatia

4 Department of Medicine and Health Sciences, University of Molise, Campobasso, Italy

5 SUN Orthopedics of Evangelical Community Hospital, Lewisburg, PA, USA

6 OrthoTrauma Evaluation Institute, Mainz, Germany

7 Department of Musculoskeletal Disorders, Faculty of Medicine and Surgery, University of Salerno, Salerno, Italy

8 Centre for Sports and Exercise Medicine, Barts and the London School of Medicine and Dentistry, Mile End Hospital, London, UK

Corresponding author:

Nicola Maffulli

Department of Musculoskeletal Disorders

School of Medicine and Surgery,

University of Salerno,

Mary University of London

Barts and the London School of Medicine and Dentistry

Centre for Sports and Exercise Medicine

Mile End Hospital 275 Bancroft Road

E1 4DG, London, England, UK

Tel.: +447989358279

E-mail: n.maffulli@qmul.ac.uk

\section{Summary}

Introduction: To determine the effectiveness of ESWT in patients suffering from plantar fasciitis in both the short and long term.

Methods: Participants were enrolled by different clinicians in the National Health Service (NHS) and private sector centres in the United Kingdom. Data were collected in a web-based database [Assessment of the Effectiveness of Extracorporeal Shock Wave Therapy (ESWT) For Soft Tissue Injuries (ASSERT)]. The 198 participants (mean age
48.17 y; range 20-82 y) were treated using a standardized ESWT protocol, and different outcome measures relative to their specific condition and health status [Visual Analogue Scale (VAS) for pain perception, the Foot Function Index (FFI) for limitations in everyday life activities, and the 6 scores of EuroQol-5D questionnaire (EQ-5D) for quality of life] were assessed at baseline, and 3, 6, 12 and 24 months following ESWT treatment.

Results: There was a significant improvement over time in 6 of the 8 analysed scores (all with $p<0.0001$ ) [VAS, FFI, and 4 scores of EQ-5D (Mobility, Pain/Discomfort, Usual Activities, and Thermometer Scale)].

Conclusion: ESWT exerts beneficial effects on PF over a 24-month follow-up period.

Level of evidence: IV.

KEY WORDS: extracorporeal shock wave therapy, longitudinal study, plantar fasciitis, plantar fasciopathy.

\section{Introduction}

Plantar fasciitis (PF) is a common cause of heel pain, and is disabling when chronic ${ }^{1}$. Its aetiology is poorly understood and probably multifactorial, and there is not a large body of evidence supporting one treatment over another ${ }^{2}$. Mechanical overload, obesity, prolonged standing and running may contribute to symptoms ${ }^{3,4}$. PF should be more correctly named "fasciopathy" given the lack of evidence of inflammation at histology 5 . The diagnosis of PF is based on the patient's history and physical examination ${ }^{6}$. Many non-surgical management options have been reported, including icing, non-steroidal anti-inflammatory medications, corticosteroid injections, Botulinum toxin A, autologous blood and platelet rich plasma injections, orthosis, and physical therapy ${ }^{7}$. These non-surgical measures generally represent the first step of treatment. Surgery is generally used in the $5-10 \%$ of patients not responding to non-operative measures for 6-12 months ${ }^{7}$.

Extracorporeal Shock Wave Therapy (ESWT) is a widely used in the management of PF, but not all trials have yielded positive results, and some of the therapeutic effects of this treatment require further investigation. For example, a recent meta-analysis of randomised controlled trials (RCTs) concluded that the lack of a long-term follow-up precluded a demonstration of the long-term efficacy of ESWT in the man- 
agement of $\mathrm{PF}^{4}$. The short-term benefits of ESWT on pain relief and function are much less controversial ${ }^{4}$. Researchers in the field have called for additional investigations, using homogenous interventions, identical outcome assessment, comparable participants, and comparable follow-up evaluations. Such studies can be performed using large database analyses ${ }^{8}$. The National Institute for Health and Clinical Excellence (NICE) recommends that the results of ESWT are monitored, and clinicians undertaking such procedure make special arrangements for audit ${ }^{9}$. The Assessment of Effectiveness of ESWT for Soft Tissue Injuries (ASSERT) is one such database, the aim of which is to determine the effectiveness of ESWT in patients suffering from selected soft tissue injuries in both the short and long term ${ }^{10}$.

This study evaluated the effectiveness of ESWT in patients with chronic insertional PF enrolled in ASSERT over 24 months considering different aspects, namely the reduction of the clinical severity of symptoms, the relief of pain, and the improvement of the quality of life. Furthermore, this study also aimed to analyse the effects that certain variables such as age, gender, menopausal status, and prior symptoms may have on outcome.

\section{Methods}

The ASSERT database was used to collect information on the effectiveness of ESWT across the United Kingdom. The ESWT machines were standardised, and a standardised treatment protocol, together with standardised baseline measurements and outcome measures and time points in centres across the United Kingdom, were adopted to aid validity ${ }^{10}$.

\section{Recruitment}

Participants were recruited from both the National
Health Service (NHS) and private sector centres in the United Kingdom. Clinicians recruited participants presenting with insertional plantar fasciitis, and for whom ESWT was indicated as the treatment choice.

\section{Participants}

Participants were included if they were over the age of 18, had a diagnosis of insertional PF confirmed by the recruiting clinician; had undergone a course of conservative therapy which had not been effective in relieving symptoms; had been recommended to receive ESWT at one of the recruiting centres; had not been diagnosed with inflammatory arthropathy; and had demonstrated the ability to give informed consent.

There were 211 participants enrolled (106 males; 105 females) and 198 participants (96 males; 102 females) considered for analysis (Tab. I).

This study has been designed and conducted in accordance with the principles of the Declaration of Helsinki and it has been approved by the Local Ethics Committee (11/LO/0253). A written informed consent was obtained by each participant ${ }^{11}$.

\section{Use of ESWT machine}

Standardisation of the machine and the process of administration of ESWT had been agreed to ensure consistency, reproducibility and generalisability of the results. All clinicians using the Swiss DolorClast device (Electro Medical Systems SA, Nyon, Switzerland) and Stortz devices (Stortz Medical AG, Tägerwilen, Switzerland) received training and certification to ensure adherence to the protocol. All clinicians followed a standardised method of administration of ESWT $^{12}$. This included delivering an initial 500 "warm-up" impulses at a low air pressure (1.5 bar of air pressure). This reduces the pain which patients experience during treatment. Based on patient feedback, the clinician then increased the air pressure to

Table I. Sample of participants.

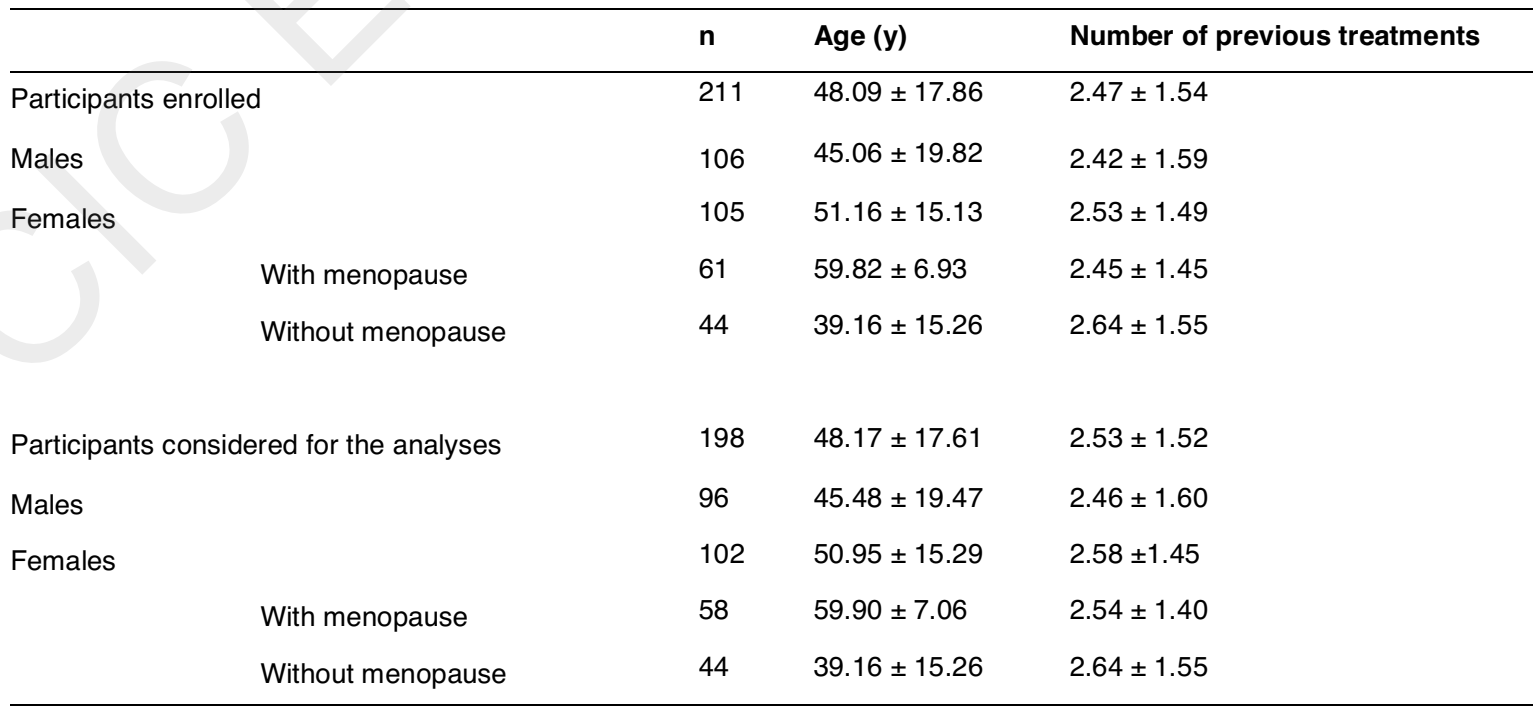


2.5 bar or above. The total dose of impulses remained constant at 2500 per session, with one session a week for three planned consecutive weeks, with a maximum gap between two consecutive treatments of two weeks.

\section{Database}

The ASSERT database is a web based system (www.assert.org.uk) from which the clinician received a study number for each participant ${ }^{10}$. Only unidentifiable information with the patients' study number was entered into the database. Sensitive data are held on secure servers. Following informed consent, the clinician recorded the following information: 1) Diagnosis: this was formulated on clinical grounds and some clinicians also used imaging to confirm the diagnosis; 2) Area treated/condition presented with; 3) Date of presentation of symptoms; 4) Date of treatment of ESWT; 5) Code for clinicians centre; 6) Centre where treatment was administered; 7) Previous treatments prior to consultation; 8) Side treated; 9) Dates when ESWT was administered; 10) Baseline scores recorded: EuroQol questionnaire scores (EQ-5D) ${ }^{13}$, Visual Analogue Scale for pain (VAS) ${ }^{14}$, and Foot Function Index $(\mathrm{FFI})^{15}$; 11) Follow-up scores at 3, 6, 12 and 24 months post treatment; 12) Satisfaction: rated poor, satisfactory, good or excellent; 13) Time to effective treatment; 14) Recurrence of the condition; 15) Complications; 16) Adverse events.

\section{Baseline and follow-up assessments}

After having obtained written informed consent, the treating clinician undertook baseline assessments. The follow-up assessments were performed after 3 , 6, 12 and 24 months' post treatment. The coordinators of ASSERT undertook all follow-up assessments via email, telephone or post.

\section{Outcome assessment}

The EQ-5D ${ }^{13}$ and VAS for pain ${ }^{14}$ were completed alongside the $\mathrm{FFI}^{15}$.

The EQ-5D is a standardised measure of health status developed by the EuroQol Group to provide a simple, generic measure of health for clinical and economic appraisal. For the present study, the version $3 L(E Q-5 D-3 L)$ was used. This is a simple questionnaire composed of 5 items with a 3-point scale answer for each item, and designed for completion by the person being treated. Each one of the 5 items respectively investigates 5 dimensions of the quality of life, namely (1) mobility, (2) self-care, (3) usual activities, (4) pain/discomfort, and (5) anxiety/depression. A score from 1 (best score) to 3 (worst score) is assigned for each dimension. The EQ-5D also includes a scale, named EQ-5D Thermometer Scale, that allows to obtain a global score to generally describe the quality of life of the patient. It consists of a vertical line, $100 \mathrm{~mm}$ in length, anchored by 2 word descriptors at each end, which are "the worst health you can imagine" and "the best health you can imagine". Patients are asked to mark on the line the point which they feel represents their perception of their current health status. The score ranges from 0 (worst health status) to 100 (best health status), and it is computed by measuring the distance (in $\mathrm{mm}$ ) between the end of the line marked with "the worst health you can imagine" and the mark on the line indicated by the patient.

The VAS for pain (or Visual Analogue Scale for pain) is very similar to the EQ-5D Thermometer Scale, but it focuses only on the pain perceived by the patient, not on the overall quality of life. It consists of a horizontal line, $100 \mathrm{~mm}$ in length, which asks the patients "How severe is your pain today?". The line is anchored by 2 word descriptors at each end, which are "no pain" and "very severe pain". Also in this case, patients mark on the line the point which they feel represents their current perception of their pain intensity. The score, from 0 (no pain) to 100 (very severe pain), is computed as the measurement of the distance (in $\mathrm{mm}$ ) between the end of the line marked with "no pain" and the point on the line indicated by the patient.

The FFI is a validated score assessing foot pain and disability. It consists of a questionnaire composed by 17 items investigating how the foot pain affects the ability to manage everyday life. For each item, the patient is asked to indicate a score form 0 (best score) to 10 (worst score). The score of the FFI is computed as [(summation of the 17 items scores /170) $\times 100]$.

\section{Statistical analysis}

A Linear Mixed Model analysis (LMM) with the Maximum Likelihood method was used to verify whether significant effects over time were produced by ESWT on the treatment of the PF. To perform the LMM analysis, two fixed factors were considered: Time factor (fixed factor: T0 vs T3 vs T6 vs T12 vs T24) to investigate differences over time, and Gender factor (fixed factor: males vs females) to investigate differences between males and females patients'. The interaction Time $\times$ Gender was also analysed. The VAS for pain, the FFI scores, and the 6 scores of the EQ-5D were considered as dependent variables for the analysis. If two or more of the follow-up datasets were missing the patient was excluded.

Successively, another LMM analysis was performed on the females participants only to evaluate differences between women before and after menopause. This analysis was performed using two fixed factors: Time factor (fixed factor: T0 vs T3 vs T6 vs T12 vs T24), and menopause factor (fixed factor: Menopause vs No-Menopause). Also in this case the interaction between the 2 factors was considered (Time $\varnothing$ Menopause). The VAS, FFI, and the 6 scores of the EQ-5D were considered as dependent variables for the analysis.

The age and the number of previous treatments were considered as covariates of the analysis to verify whether these factors could have influenced the analysed scores over time. 
Given the multiple dependent variables, the Bonferroni correction was used to adjust the $p$ value. The Bonferroni correction indicate an adjusted p-value $<0.006$ for significance.

When a significant effect over time was detected, Bonferroni post-hoc analysis was used to perform comparisons in pair among the different time of assessments.

The analyses were performed using SPSS 20 (IBM Corporation, Chicago, IL, USA).

\section{Results}

The scores and the results of the post-hoc analysis are reported in Table II.

There was a significant reduction over time of the VAS for pain score $\left(F_{4,426}=159.394 ; p<0.0001\right)$, whereas no significant differences were found between the two genders $\left(F_{1,205}=4.638 ; p=0.032 ; p\right.$ value not significant after Bonferroni correction for multiple variables) and in the interaction TimexGender $\left(F_{4,426}=1.217 ; p=0.303\right)$.

The FFI scores showed a significant decrement over

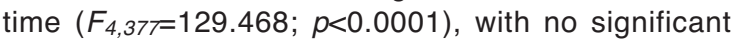
differences between the two genders $\left(F_{1,190}=2.895\right.$; $p=0.091)$ and in the interaction Time $\times$ Gender $\left(F_{4,377=3.403 ;} p=0.009\right.$; not significant after Bonferroni correction).

Concerning the EQ-5D questionnaire domains, the EQ-5D Anxiety/Depression score did not show significant differences both in Time $\left(F_{4,390}=2.938 ; p=0.021\right.$; not significant after Bonferroni correction) and Gen$\operatorname{der}\left(F_{1,166}=0.125 ; p=0.724\right)$, and similarly also in the interaction TimexGender $\left(F_{4,390}=1.150 ; p=0.333\right)$.

Significant reduction over time were instead found in the EQ-5D Mobility score $\left(F_{4,428}=41.975 ; p<0.0001\right)$, but no significant differences between the two genders $\left(F_{1,183}=2.502 ; p=0.115\right)$ and in the interaction TimexGender $\left(F_{4,428}=0.646 ; p=0.630\right)$ were evident. Significant reduction over time was found also in the EQ-5D Pain/Discomfort score $\left(F_{4,418}=57.701\right.$; $p<0.0001)$, with no significant differences between the two genders $\left(F_{1,193}=4.102 ; p=0.044\right.$; not significant after Bonferroni correction) and in the interaction TimexGender $\left(F_{4,418}=0.691 ; p=0.599\right)$.

The analysis showed once again a significant reduction over time of the EQ-5D Usual Activities score $\left(F_{4,430}=53.147 ; p<0.0001\right)$, with no significant differences between the two genders $\left(F_{1,198}=0.727\right.$; $p=0.395)$ and in the interaction Time $\times$ Gender $\left(F_{4,430}=0.649 ; p=0.628\right)$.

Conversely, the EQ-5D Self-Care did not show significant differences both in Time $\left(F_{4,370}=1.513 ; p=0.198\right)$ and Gender $\left(F_{1,177}=1.869 ; p=0.173\right)$, and in the interaction Time $\times$ Gender $\left(F_{4,370}=1.423 ; p=0.226\right)$.

Finally, the EQ-5D Thermometer Scale analysis showed significant differences in Time $\left(F_{4,374}=14.198\right.$; $p<0.0001)$, but no differences were found between genders $\left(F_{1,169}=0.489 ; p=0.485\right)$, and in the interaction TimexGender $\left(F_{4,374}=0.473 ; p=0.755\right)$.

The involvement in previous treatment(s) and the age of the patients did not produce significant influences on all the analysed dependent variables (non-significant $p$-values for all the variables).

The LMM analysis on the females participants performed to evaluate whether differences existed in the analysed variables between females patients before and after menopause showed no differences in any analysed variables.

\section{Discussion}

The main finding of the present study is that the significant beneficial effects of ESWT in the management of PF reported by single centre investigative team are confirmed when the intervention is carried out by different investigators using homogenous ESWT administration regimens, with significant amelioration in 6 of the 8 analysed variables. The primary results are that 1) ESWT is safe and effective, yielding significant improvements in pain and function, 2) these results last for 24 months, and 3) gender, age or menopausal status do not affect results.

ESWT produced significant positive effects in reducing pain, and improving the ability of the patients to manage everyday life as indicated by the significant amelioration of VAS and FFI score respectively. Also, the quality of life and the health status resulted significantly enhanced after ESWT intervention as suggested by the overall improvement of EQ-5D scores, with the only exception of Anxiety/Depression and Self-Care dimensions' scores. However, the baseline scores of these two dimensions (Tab. II) were substantially low, and they remained low for all the duration of the follow-up. Consequently, the non-significant modification of these two scores was probably attributable to a low impact of PF on these 2 dimensions since the baseline assessment.

Another clinically important finding concerns the time necessary to obtain significant benefits on health status and pain relief. In fact, there was a significant improvement three months after the last session of ESWT in VAS, FFI, EQ-5D Mobility, EQ-5D Pain/Discomfort, and EQ-5D Usual Activities. Only the EQ-5D Thermometer Scale score needed 6 months for a significant amelioration in comparison to the baseline score. This seems to indicate that the global perception of health status requires more time to improve compared to the amelioration of the single dimensions analysed separately. Given these results, ESWT can be considered a valid and effective method for the treatment of PF. Furthermore, this study also found that the engagement in previous treatments, the age, the gender and the presence/absence of menopause seems to exert no significant influence on the efficacy of ESWT. The influence of these factors was generally not considered in previous studies, and could represent an additional strength for the use of this modality in the management of PF, regardless of gender or age.

The results of the present study are in accordance with recent meta-analyses performed in $2013^{16}$, 
Table II. Results relative to the effects over time with the post-hoc analyses outputs.

\begin{tabular}{|c|c|c|c|c|c|c|c|c|}
\hline \multirow[t]{2}{*}{ Tests } & & TO & T3 & T6 & T12 & T24 & \multirow{2}{*}{$\begin{array}{l}\text { Overall } \\
\text { significance } \\
\text { in time }\end{array}$} & \multirow{2}{*}{$\begin{array}{l}\text { Comparisons } \\
\text { in pair - } \\
\text { significance }\end{array}$} \\
\hline & & $\begin{array}{l}\text { Means } \pm \\
\text { SD (N) }\end{array}$ & $\begin{array}{l}\text { Means } \pm \\
\text { SD (N) }\end{array}$ & $\begin{array}{l}\text { Means } \pm \\
\text { SD (N) }\end{array}$ & $\begin{array}{l}\text { Means } \pm \\
\text { SD (N) }\end{array}$ & $\begin{array}{l}\text { Means } \pm \\
\text { SD (N) }\end{array}$ & & \\
\hline \multirow[t]{2}{*}{ VAS for pain } & Scores & $\begin{array}{l}59.79 \pm \\
21.41(184)\end{array}$ & $\begin{array}{l}31.31 \pm \\
28.90 \\
(128)\end{array}$ & $\begin{array}{l}20.24 \pm \\
25.20 \\
(103)\end{array}$ & $\begin{array}{l}12.81 \pm \\
23.77 \\
(90)\end{array}$ & $\begin{array}{l}9.15 \pm \\
19.78 \\
(79)\end{array}$ & \multirow[t]{2}{*}{$p<0.0001$} & \multirow{2}{*}{$\begin{array}{l}\text { T0 vs T3, T6, } \\
\text { T12, T24 } \\
\text { T3 vs T6, T12, } \\
\text { T24 } \\
\text { T6 vs T24 }\end{array}$} \\
\hline & $\begin{array}{l}\text { Difference } \\
\text { with } \\
\text { baseline } \\
\text { score }\end{array}$ & & -28.48 & -39.55 & -46.98 & -50.64 & & \\
\hline \multirow[t]{2}{*}{ Foot Function Index } & Scores & $\begin{array}{l}48.59 \pm \\
18.48(151)\end{array}$ & $\begin{array}{l}25.35 \pm \\
23.89 \\
(110)\end{array}$ & $\begin{array}{l}18.45 \pm \\
20.35 \\
(100)\end{array}$ & $\begin{array}{l}12.02 \pm \\
18.84 \\
(90)\end{array}$ & $\begin{array}{l}8.61 \pm \\
17.60 \\
(76)\end{array}$ & \multirow[t]{2}{*}{$p<0.0001$} & \multirow{2}{*}{$\begin{array}{l}\text { T0 vs T3, T6, } \\
\text { T12, T24 } \\
\text { T3 vs T6, T12, } \\
\text { T24 } \\
\text { T6 vs T24 }\end{array}$} \\
\hline & $\begin{array}{l}\text { Difference } \\
\text { with } \\
\text { baseline } \\
\text { score }\end{array}$ & & -23.24 & -30.14 & -36.57 & -39.98 & & \\
\hline \multirow[t]{2}{*}{$\begin{array}{l}\text { EQ-5D } \\
\text { Anxiety/Depression }\end{array}$} & Scores & $\begin{array}{l}1.31 \pm 0.52 \\
(179)\end{array}$ & $\begin{array}{l}1.20 \pm \\
0.44 \\
(121)\end{array}$ & $\begin{array}{l}1.20 \pm \\
0.40 \\
(102)\end{array}$ & $\begin{array}{l}1.21 \pm \\
0.46(90)\end{array}$ & $\begin{array}{l}1.12 \pm \\
0.36(76)\end{array}$ & \multirow[t]{2}{*}{ Not significant } & \multirow[t]{2}{*}{-} \\
\hline & $\begin{array}{l}\text { Difference } \\
\text { with } \\
\text { baseline } \\
\text { score }\end{array}$ & - & -0.11 & -0.11 & -0.10 & -0.19 & & \\
\hline \multirow[t]{2}{*}{ EQ-5D Mobility } & Scores & $\begin{array}{l}1.76 \pm 0.45 \\
(179)\end{array}$ & $\begin{array}{l}1.45 \pm \\
0.5(121)\end{array}$ & $\begin{array}{l}1.35 \pm \\
0.48 \\
(102)\end{array}$ & $\begin{array}{l}1.24 \pm \\
0.43(90)\end{array}$ & $\begin{array}{l}1.13 \pm \\
0.34(76)\end{array}$ & \multirow[t]{2}{*}{$p<0.0001$} & \multirow{2}{*}{$\begin{array}{l}\text { T0 vs T3, T6, } \\
\text { T12, T24 } \\
\text { T3 vs T12, T24 } \\
\text { T6 vs T24 }\end{array}$} \\
\hline & $\begin{array}{l}\text { Difference } \\
\text { with } \\
\text { baseline } \\
\text { score }\end{array}$ & & -0.31 & -0.41 & -0.52 & -0.63 & & \\
\hline \multirow[t]{2}{*}{ EQ-5D Pain/Discomfort } & Scores & $\begin{array}{l}2.11 \pm 0.47 \\
(179)\end{array}$ & $\begin{array}{l}1.73 \pm \\
0.66 \\
(121)\end{array}$ & $\begin{array}{l}1.59 \pm \\
0.60 \\
(102)\end{array}$ & $\begin{array}{l}1.36 \pm \\
0.55(90)\end{array}$ & $\begin{array}{l}1.29 \pm \\
0.56(76)\end{array}$ & \multirow[t]{2}{*}{$p<0.0001$} & \multirow{2}{*}{$\begin{array}{l}\text { T0 vs T3, T6, } \\
\text { T12, T24 } \\
\text { T3 vs T12, T24 } \\
\text { T6 vs T12, T24 }\end{array}$} \\
\hline & $\begin{array}{l}\text { Difference } \\
\text { with } \\
\text { baseline } \\
\text { score }\end{array}$ & & -0.38 & -0.52 & -0.75 & -0.82 & & \\
\hline \multirow[t]{2}{*}{ EQ-5D Usual Activities } & Scores & $\begin{array}{l}1.85 \pm 0.46 \\
(179)\end{array}$ & $\begin{array}{l}1.44 \pm \\
0.59 \\
(121)\end{array}$ & $\begin{array}{l}1.35 \pm \\
0.57 \\
(102)\end{array}$ & $\begin{array}{l}1.20 \pm \\
0.48(90)\end{array}$ & $\begin{array}{l}1.14 \pm \\
0.39(76)\end{array}$ & \multirow[t]{2}{*}{$p<0.0001$} & \multirow[t]{2}{*}{$\begin{array}{l}\text { T0 vs T3, T6, } \\
\text { T12, T24 } \\
\text { T3 vs T12, T24 }\end{array}$} \\
\hline & $\begin{array}{l}\text { Difference } \\
\text { with } \\
\text { baseline } \\
\text { score }\end{array}$ & - & -0.41 & -0.50 & -0.65 & -0.71 & & \\
\hline \multirow[t]{2}{*}{ EQ-5D Self-Care } & Scores & $\begin{array}{l}1.14 \pm 0.35 \\
(179)\end{array}$ & $\begin{array}{l}1.05 \pm \\
0.22 \\
(121)\end{array}$ & $\begin{array}{l}1.06 \pm \\
0.24 \\
(102)\end{array}$ & $\begin{array}{l}1.06 \pm \\
0.27(90)\end{array}$ & $\begin{array}{l}1.04 \pm \\
0.20(76)\end{array}$ & \multirow[t]{2}{*}{ Not significant } & \multirow[t]{2}{*}{-} \\
\hline & $\begin{array}{l}\text { Difference } \\
\text { with } \\
\text { baseline } \\
\text { score }\end{array}$ & - & -0.09 & -0.08 & -0.08 & -0.10 & & \\
\hline \multirow[t]{2}{*}{$\begin{array}{l}\text { EQ-5D Thermometer } \\
\text { Sc. }\end{array}$} & Scores & $\begin{array}{l}67.74 \pm \\
23.08(179)\end{array}$ & $\begin{array}{l}73.39 \pm \\
22.07 \\
(121)\end{array}$ & $\begin{array}{l}79.31 \pm \\
17.85 \\
(102)\end{array}$ & $\begin{array}{l}83.94 \pm \\
16.36 \\
(90)\end{array}$ & $\begin{array}{l}84.37 \pm \\
17.48 \\
(76)\end{array}$ & \multirow[t]{2}{*}{$p<0.0001$} & \multirow{2}{*}{$\begin{array}{l}\text { T0 vs T6, T12, } \\
\text { T24 } \\
\text { T3 vs T6, T12, } \\
\text { T24 }\end{array}$} \\
\hline & $\begin{array}{l}\text { Difference } \\
\text { with } \\
\text { baseline } \\
\text { score }\end{array}$ & & +5.65 & +11.57 & +16.20 & +16.63 & & \\
\hline
\end{tabular}

$p$-value for significance after Bonferroni correction is $<0.006$ 
$2014^{4}$ and in $2017^{17,18}$, confirming that ESWT is safe and effective in the non surgical management of PF. In particular, Aqil et al. ${ }^{16}$ recommend the use of ESWT in patients with substantial heel pain when other non-operative treatment resulted ineffective after a minimum of 3 months. However, the literature also reported that larger sample and high-quality clinical trials and systematic reviews are necessary to demonstrate the efficacy of ESWT ${ }^{18}$, and also long term follow-up studies are needed to better define the efficacy of ESWT in the long term ${ }^{4}$, In this respect, the ASSERT database plays an important role. In fact, ASSERT aimed to collect high quality and relevant data about the effectiveness of ESWT in patients with PF in a pragmatic and systematic manner to improve the quality of outcomes and ensure the quality and cost effectiveness of ESWT. ASSERT can monitor the outcomes achieved by practitioners and identify where these fall below an expected performance to inform best practice and additional training requirements.

Some studies reported no effects of ESWT ${ }^{19,20}$ in the treatment of PF, and some aspects of this modality remain unclear. The present evidence ${ }^{4,16-18}$ however clearly indicates ESWT as an effective therapy for the management of PF. No study is perfect, and we acknowledge that many other variables such as the amount of energy employed, high vs low intensity shock wave treatment, radial vs focused shock wave treatment, the methods of localization of the shock waves, the number of shocks, and the number of sessions must also be considered when evaluating the efficacy of ESWT. Nevertheless, we point out that the protocol used to administer extracorporeal shock wave treatment in ASSERT is based on the evidence produced by Level I studies in this field21,22. Nevertheless, we acknowledge that more high-quality and well-conducted studies are necessary. A database such as ASSERT could be a valid method for the systematic collection of large amount of data and for the standardization of procedures to obtain strong evidences in this field.

Concerning the limitations, this study is not a randomised controlled trial. However, Level I studies have been conducted in the present field, and have shown that ESWT, when administered according to evidence based well established protocols ${ }^{21,22}$, is safe and effective in the management of the condition at hand. The National Institute for Health and Clinical Excellence (NICE) suggested that the effectiveness of ESWT in "real life" would have needed to be evaluated in a pragmatic fashion, using standardised protocols and well validated clinically relevant outcome measures. The ASSERT protocol is NICE compliant, and satisfies the requirements set out by NICE ${ }^{9}$.

The fact that many different clinicians were involved in the treatment, after appropriate certified training and standardisation of the protocol, and that the effects of treatment were evaluated by independent individuals, increases the generalizability of the present findings, and, in this respect, should be considered a major strength of the present study. Also, all patients had previously failed a variety of conservative management means, and this was a major criterion to be recruited in the present study ${ }^{21}$.

In conclusion, when administered in a standardised fashion to an unselected population of patients suffering from insertional plantar fasciopathy, ESWT therapy is safe and effective in alleviating symptoms for up to 24 months.

\section{Compliance with ethical standards}

\section{Conflict of interest}

All Authors declare no conflict of interest.

\section{Funding}

The ASSERT Database has been developed and established through funds provided by Industry (Spectrum Technology UK) and ESPRC grants.

\section{Acknowledgements}

We thank Mr Jim Westwood and Mr Chris Schiel from Spectrum Technology for their support. Mr Nathan Bentley of twotwentyseven London Ltd - a creative digital agency developed the ASSERT platform following the direction of Professor Nicola Maffulli and Mrs Gayle Maffulli.

We thank all the clinicians recruiting participants onto the ASSERT database and the participants of ASSERT. Professor Nicola Maffulli developed the concept of ASSERT.

\section{Ethical approval}

All procedures performed in this study involving human participants were in accordance with the ethical standards of the institutional and/or national research committee and with the 1964 Helsinki declaration and its later amendments or comparable ethical standards.

\section{Informed consent}

Informed consent was obtained from all individual participants included in the study.

\section{References}

1. Mahindra P, Yamin M, Selhi HS, Singla S, Soni A. Chronic Plantar Fasciitis: Effect of Platelet-Rich Plasma, Corticosteroid, and Placebo. Orthopedics. 201639:e285-e289.

2. Wrobel JS, Fleischer AE, Matzkin-Bridger J, Fascione J, Crews RT, Bruning N, et al. Physical Examination Variables Predict Response to Conservative Treatment of Nonchronic Plantar Fasciitis: Secondary Analysis of a Randomized, Placebo-Controlled Footwear Study. PM R. 2006;8:436-444. 
3. Goecker RM, Banks AS. Analysis of release of the first branch of the lateral plantar nerve. J Am Podiatr Med Assoc. 2000;90:281-286.

4. Yin MC, Ye J, Yao M, Cui XJ, Xia Y, Shen QX, et al. Is Extracorporeal Shock Wave Therapy Clinical Efficacy for Relief of Chronic, Recalcitrant Plantar Fasciitis? A Systematic Review and Meta-Analysis of Randomized Placebo or Active-Treatment Controlled Trials. Arch Phys Med Rehabil. 2014;95: 1585-1593.

5. Schwartz EN, Su J. Plantar Fasciitis: A Concise Review. Perm J. 2014;18:e105-e107.

6. Cole C, Seto C, Gazewood J. Plantar fasciitis: evidence-based review of diagnosis and therapy. Am Fam Physician. 2015;72: 2237-2242.

7. Gohiya A, Choudhari P, Sharma P. Plantar fasciitis treatment. Orthop J MP Chapter. 2016;22:31-37.

8. Rompe JD, Maffulli N. Repetitive shock wave therapy for lateral elbow tendinopathy (tennis elbow): a systematic and qualitative analysis. Br Med Bull. 2007;83:355-378.

9. National Institute for Health and Care Excellence (NICE). Extracorporeal shockwave therapy for refractory plantar fasciitis. 2009. https://www.nice.org.uk/guidance/ipg311/chapter/1Guidance.

10. Maffulli G, Hemmings S, Maffulli N. Assessment of the Effectiveness of Extracorporeal Shock Wave Therapy (ESWT) For Soft Tissue Injuries (ASSERT): An Online Database Protocol. Transl Med @ UniSa. 2014;10:46-51.

11. Padulo J, Oliva F, Frizziero A, Maffulli N. Muscles, Ligaments and Tendons Journal. Basic principles and recommendations in clinical and field science research: 2016 update. MLTJ 2016;6(1):1-5.

12. Gerdesmeyer L, Wagenpfeil S, Haake M, Maier M, Loew M, Wörtler K, et al. Extracorporeal Shock Wave Therapy for the Treatment of Chronic Calcifying Tendonitis of the Rotator Cuff: a randomized controlled trial. JAMA. 2003;290:2573-2580.
13. EuroQol-Group. EuroQol: a new facility for the measurement of health related quality of life. Health Policy. 1990;16:199-208.

14. Scott J, Huskisson EC. Graphic representation of pain. Pain. 1976;2:175-184.

15. Budiman-Mak E, Conrad KJ, Roach KE. The foot function index: A measure of foot pain and disability. J Clin Epidemiol. 1991;4:561-570.

16. Aqil A, Siddiqui MRS, Solan M, Redfern DJ, Gulati V, Cobb JP. Extracorporeal Shock Wave Therapy Is Effective in Treating Chronic Plantar Fasciitis: A Meta-analysis of RCTs. Clin Orthop Relat Res. 2013;471:3645-3652.

17. Lou J, Wang S, Liu S, Xing G. Effectiveness of Extracorporeal Shock Wave Therapy Without Local Anesthesia in Patients with Recalcitrant Plantar Fasciitis. Am J Phys Med Rehabil. 2017;96:529-534.

18. Sun J, Gao F, Wang Y, Sun W, Jiang B, Li Z. Extracorporeal shock wave therapy is effective in treating chronic plantar fasciitis: A meta-analysis of RCTs. Medicine(Baltimore). 2017;96:6621.

19. Haake M, Buch M, Schollner C, Goebel F, Vogel M, Mueller I, et al. Extracorporeal shock wave therapy for plantar fasciitis: randomised controlled multicentre trial. BMJ. 2003;327:75.

20. Speed CA, Nichols D, Wies J, Humphreys H, Richards C, Burnet $S$, et al. Extracorporeal shock wave therapy for plantar fasciitis. A double blind randomised controlled trial. J Orthop Res. 2003;21:937-940.

21. Rompe JD, Cacchio A, Weil L Jr, Furia JP, Haist J, Reiners V, et al. Plantar Fascia-Specific Stretching Versus Radial ShockWave Therapy as Initial Treatment of Plantar Fasciopathy. J Bone Joint Surg Am. 2010;92:2514-2522.

22. Rompe JD, Furia J, Cacchio A, Schmitz C, Maffulli N. Radial shock wave treatment alone is less efficient than radial shock wave treatment combined with tissue-specific plantar fasciastretching in patients with chronic plantar heel pain. Int J Surg. 2015;24:135-142. 